\title{
The Flipped Classroom Experience of Gamified
}

\author{
Tae Matsumoto \\ Kanto Gakuin University, Yokohama, Japan \\ Email: tmatumot@kanto-gakuin.ac.jp
}

Received 30 May 2016; accepted 10 July 2016; published 13 July 2016

Copyright (C) 2016 by author and Scientific Research Publishing Inc.

This work is licensed under the Creative Commons Attribution International License (CC BY).

http://creativecommons.org/licenses/by/4.0/

(c) (i) Open Access

\begin{abstract}
There has recently been growing interest in the area of gamification, the application of game elements to non-game contexts. This concept has been put to use in several different fields, one such field being education. What is good about game-informed learning is that when conditions are satisfied, learners can enhance their intrinsic motivation towards goal achievement. For the purpose of the study, two types of discussion were utilized: gamification and flipped classroom. The flipped classroom used technology to access the lecture and other instructional resources outside the classroom. This paper proposes the flipped classroom support methods using the Gamification. In order to discuss the pros and cons of gamification of education, the authors conducted an experiment and questionnaire using flipped classroom with gamification elements for English as foreign language education. The results of this study particularly highlighted the importance of well-designed tutorial, task, interface and feedback for the effective game-based e-learning. It is an inverted version of the traditional learning model.
\end{abstract}

\section{Keywords}

E-Learning, Gamification, Motivation, Flipped Classroom

\section{Introduction}

The flipped classroom is becoming increasingly well known around the University education in Japan. It has become a new way of teaching approach. The flipped classrooms are able to remodel large lecture classes into active-learning. Active learning is a key aspect of the flipped classroom. In flipped classrooms, students watch videos and online lectures outside of class, and valuable class time is used to solve problems and apply concepts. It should also be added that the flipped classroom model is a blended learning strategy. However, it is still at the early stage in Japan. As a reason for this might be the lack of good quality electronic learning materials and teaching method. In addition, according to the drop out white paper, the number of university student is dropout 
increases rapidly and it becomes a big problem in recent years. In the background of such an awareness of the issues, I suggest that instructional design framework. The proposed method is a lot different from existing methods (Matsumoto, 2010). The following approach is employed in instructional design framework of "flipped classroom on the basis of gamification". Recently, growing attention has been paid to game-informed education. Gamification is not equal to games (Fujimoto, 2015). A game is structured play, usually for enjoy. Gamification is a strategy for influencing and motivating the behavior of people (Matsumoto, 2012). We use game design elements in non-game contexts. It means an implementation and use of game design elements and techniques. I propose the flipped classrooms support methods using the gamification. The proposed method based on the gamification could overcome the already mentioned.

\section{Existing Flipped Classroom Support Methods}

\subsection{Flipped Classroom}

The traditional classroom environment is face-to-face only. The relevant classroom formats are face-to-face, virtual, and blended. And yet, the needs of video contents for flipped classroom and Massive Open Online Courses (MOOCs) have been increasing rapidly. However, blended learning, which combines online and faceto-face elements, yielded better. For example, absent students appreciated the opportunity to see what they missed. But, so did students who hadn't missed class. Online learning can continue outside the classroom. E-Learning stands for electronic learning and is the application of electronic media and/or information and communication technologies to education. One of the most frequently mentioned positive aspect of e-Learning is that it can overcome problems related to space and time. This is to say, with electronic devices (e.g., a personal computer) and, in many cases, internet connection, learners can conduct wherever they are and whenever they want. However, as a downside, it has also been pointed out that e-Learning will not be a productive learning method for learners with weak motivation and self-regulation ability. This downside particularly applies to independent e-Leaning (e.g., using Videos, or computer programs for self-learning). As more fully described below, by adding self-learning facilitating elements to the current e-learning system, gamification can provide a solution to this problem.

\subsection{Existing E-Learning Support Methods}

I would like to introduce existing e-Learning support methods. Existing E-learning support methods are roughly classified into three types as follows. First type is blended learning, which is an approach to integrate different learning environments. Although it is effective to have students be interested, namely to prevent from degrading the dropout rate, there is another disadvantage of schedule restriction. Second type is mentor support. Mentor is a supervisor who promotes and advocates each e-learning student. Mentor support keeps the motivation of each student, but the more the number of supporting students, the higher load the mentor must have Third type is PSI that stands for Personalized System of Instruction. This is a mastery learning model which improves the mastery of each e-learning student about his/her pre-specified set of classes. For the effective use of PSI, it requires study materials that are usually taken from course books with considerable modifications. Thus the development cost for PSI is a restriction. In addition, here is another restriction of human resource, namely training proctors for PSI. From the above-mentioned result, there is a limit to existing e-learning support methods. So other new e-Learning support methods are necessary. We propose several e-learning support methods using the gamification.

\section{Gamification of Education}

\subsection{Gamification}

Recently, growing attention has been paid to game-informed education. Gamification is one form of the above game-informed education. Gamification is a new coinage. We use of game design elements in non-game contexts. It means an implementation and use of game design elements and techniques. According to Zichermann and Cunningham, gamification is an application of game dynamism and system to real-life problem-solving (Zichermann \& Cunningham, 2011). In that sense, game-based teaching and learning can be considered to be education with gamification elements. What is good about game-informed learning is that when conditions are satisfied, learners can enhance their intrinsic motivation towards goal achievement and eventually become 
autonomous agents of learning. Gamification is one form of the above game-informed education. Thus, in game-based learning, it is essential that learners are first informed (at least) the minimal set of rules applicable to problem-solving though the tutorial. Another important role of the tutorial is informing learners of an ultimate goal of their activity. When we start playing a game, we will soon enough understand the goal of the game. In other words, we are given an ideal image of ourselves in this phase. We follow the guidance of the game because we understand that the tutorial is the first step to become someone who can accomplish the goal of game.

\subsection{Gamification Design for the E-Learning (GDE)}

E-Learning stands for electronic learning and is the application of electronic media and/or information and communication technologies to education. One of the most frequently mentioned positive aspect of e-Learning is that it can overcome problems related to space and time. This is to say, with electronic devices and, in many cases, internet connection; learners can conduct wherever they are and whenever they want. However, e-learning has major three disadvantages of high dropout rates, degrading motivation and lack of community support. To sum up, as a downside, it has also been pointed out that e-Learning will not be a productive learning method for learners with weak motivation and self-regulation ability. According to Frankola, online learners have a high drop-out rate (Frankola, 2001). There are many theories about how and why students are motivated online. The field of psychology has many theories of motivation. There are two types of motivation: intrinsic and extrinsic. Intrinsic motivation can be defined as motivation that comes from inside an individual rather than from any external or outside rewards, such as money or grades. People tend to become much more motivated to study when their friends tell them that studying is fun, than when their teachers and/or bosses tell them to study. Thus, we propose several e-learning support methods using gamification. Theory of Gamification Design for the e-Learning (GDE) from the field of Education is a guide for instructional designers to help them create course content that is appropriate for a diverse group of learners (Keller, 2004; Keller, 2010). GDE is that courses should be designed so that students can demonstrate learning in a variety of ways.

\section{Research Objectives}

Although flip teaching studies recently have started to pay attention to the effectiveness of gamification of e-learning, this research field is still in its infancy. Hence, this study decided to broaden the field. In particular, this study focused on the effectiveness of e-Learning with gamification elements. This study conducted an experiment and questionnaire using e-Learning with gamification elements for flip teaching (foreign language) education in order to illustrate how gamification elements or their absence cause motivation and demotivation in the learning experience.

\section{Surala}

Super Rapid Accumulation of Lasting Abilities (Surala) is an online educational system with gamification elements such as the visualization of progress and goals, competition against other learners, and a gradual difficulty curve with small steps at a time.

\section{Method}

\subsection{Participants}

A total of 174 Japanese English as flip teaching learners were sampled in this study. The sample consisted of 126 males and 48 females. The participated to all students in the 7th grade from a junior high school located in Shikoku (one of the four main regions in Japan). This school is private middle school. The average score of this junior school was slightly less than 52 , which means their academic level was relatively low. The questionnaire survey was conducted in November 2013. Before the survey, the participants had used Surala (e.g., "Surala is Gamification Design for the e-Learning") for the English class which was held twice a week from April to December of 2013.

\subsection{Questionnaire}

An open-ended questionnaire was employed in this study. The open-ended method was taken because very few 
studies made mentions of pros and cons of e-learning with gamification elements. The following questions were used in this study: "What do you think about GDE?" and "Do you think GDE was good for your English learning?”

\subsection{Data Analysed}

The anonymous questionnaire was distributed by the homeroom teacher and filled out by participants in the classroom. After the data collection, this study first eliminated invalid responses such as blanks and "nothing special". At the end, a total of 164 (116 males and 48 females) descriptive responses were retained for data analysis. Next, this study eliminated invalid responses such as blanks and "nothing special" opinions from free description questionnaire answer sentences. At the end, a total of 105 (75 males and 30 females) descriptive responses were retained for data analysis. Free written data of 105 students were analyzed using quantitative text analysis. In order to evaluate the pro and cons of e-learning with gamification elements (GDE), this study employed the framework introduced in Sykes and Reinhardt (Sykes \& Reinhardt, 2012). Therefore, effectiveness of tutorial, task, interface and feedback became the points of analysis. Because open-ended questions do not provide numeric data, this study only focused on how the participants evaluated the application of GDE after their 1 years of learning experience, and did not investigate the relationship between their evaluation and their learning behaviour or language gains.

\section{Result and Discussion}

This study first detected 174 descriptions which directly evaluated the effectiveness of GDE. Table 1 , shows the ratio of funny and boredom evaluations. After the data collection, this study first eliminated invalid responses such as blanks and "nothing special". At the end, a total of 164 (116 males and 48 females) descriptive responses were retained for data analysis. Next, this study eliminated invalid responses such as blanks and "nothing special” opinions from free description questionnaire answer sentences. At the end, a total of 105 (75 males and 30females) descriptive responses were retained for data analysis. Free written data of 105 students were analyzed using quantitative text analysis. Out of 105, 95 were positive evaluations (e.g., "GDE? is useful for self-learning.”) and the remaining 10 were negative evaluations (e.g., "I want to stop using GDE?”, "I do not see the point of learning."). The following results were obtained: Figure 1 shows the ratio of negative and positive evaluations. The obtained date suggest that we can see in Figure 1, the majority of participants evaluated in GDE positive. Table 2 reports information from these data provided the key word to understand the reason for

Table 1. [Gamification e-learning] Junior high school student $(\mathrm{n}=164)$.

\begin{tabular}{ccccc} 
Question & yes & no & Not sure \\
Funny & 69 & 54 & 41 \\
Boredom & 31 & 60 & 64 \\
\hline
\end{tabular}

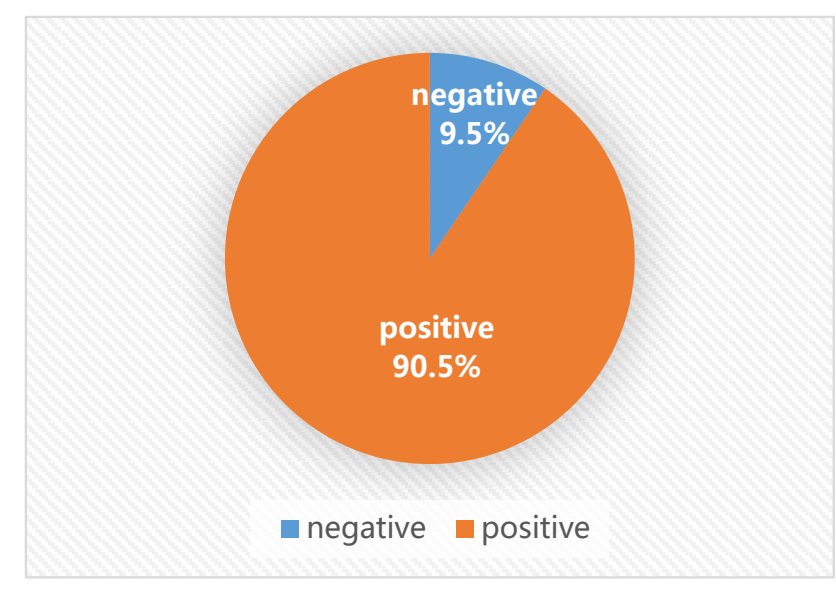

Figure 1. Evaluation ratio $(\mathrm{n}=105)$. 
Table 2. [Free written data] Junior high school student $(n=105)$.

\begin{tabular}{ccc}
\hline Negative & Comment & Positive \\
\hline 1 & Interesting & 32 \\
2 & Amusing & 5 \\
0 & Comprehensible. & 2 \\
1 & It is not easy to use it. & 11 \\
0 & English came to like it. & 6 \\
0 & Assistance message & 2 \\
0 & Ranking & 6 \\
0 & Voice & 3 \\
0 & Game & 5 \\
3 & The subject is expanded. & 6 \\
\hline
\end{tabular}

this. Reason for the positive evaluation was easy to understand explanation $(n=17)$. 95 participants positively evaluated the detailed explanations and high intelligibility of GDE. In addition, one of them even mentioned his self-growth in English. These comments demonstrated that GDE are certainly effective in nurturing positive learning attitudes to some extent. Out of the 10 negative evaluations, 3 descriptions were the discontent with the interface. The remaining 3 participants were dissatisfied with the character recognition system.

\section{Conclusion}

The findings of this study can be boiled down to the following statement: in order to conduct fruitful e-learning with gamification elements in the field of flip teaching (foreign language) education, it is important to consider the characteristics of the learners as well as pedagogies' ideal level of achievement. The findings of this study will be an informative source for future studies. The limitation of this study lies in its narrow focus. It is clear that make the Gamification based contents more creativity and keep student's motivation of learning high.

\section{References}

Frankola, K. (2001). Why Online Learners Drop out. Workforce: HR Trends \& Tools for Business Results.

Fujimoto, T. (2015). Japan Society for Educational Technology Development and Practice of Gamified Coursework Design Framework. Educational Practice Research, 38, 351-361.

Keller, J. M. (2004). A Predictive Model of Motivation, Volition, and Multimedia Learning. An Invited Keynote Speech at ICOME, 9-20.

Keller, J. M. (2010). Motivational Design for Learning and Performance: The ARCS Model Approach. Springer. http://dx.doi.org/10.1007/978-1-4419-1250-3

Matsumoto, T. (2010). Development of Manga Based e-Learning Contents in Accordance with the ADDIE Model and Its Evaluation. Annual Report of Graduate Division of Human Culture, 26, 251-259.

Matsumoto, T. (2012). Possibility of e-Learning by Using Gamification. Japanese Society for Information and Systems in Education, 27, 35-40.

Sykes, J., \& Reinhardt, J. (2012). Language at Play: Digital Games in Second and Foreign Language Teaching and Learning. New York: Pearson.

Zichermann, G., \& Cunningham, C. (2011). Gamification by Design: Implementing Game Mechanics in Web and Mobile Apps. Sebastopol, CA: O’Reilly Media. 


\section{Submit or recommend next manuscript to SCIRP and we will provide best service for you:}

Accepting pre-submission inquiries through Email, Facebook, Linkedin, Twitter, etc A wide selection of journals (inclusive of 9 subjects, more than 200 journals)

Providing a 24-hour high-quality service

User-friendly online submission system

Fair and swift peer-review system

Efficient typesetting and proofreading procedure

Display of the result of downloads and visits, as well as the number of cited articles

Maximum dissemination of your research work

Submit your manuscript at: http://papersubmission.scirp.org/ 